\title{
Experimental Study on Pile-Soil Interaction Response in Saturated Sand under Long-Term Horizontal Cyclic Loading
}

\author{
Lei Xing $\mathbb{D}^{1},{ }^{1}$ Duoyin Wang $\mathbb{D},{ }^{1,2}$ Li Wang $\mathbb{D}^{1},{ }^{1}$ Meiling Fan $\mathbb{D}^{1},{ }^{1}$ and Lunliang Duan $\mathbb{D}^{1,2,3}$ \\ ${ }^{1}$ College of River and Ocean Engineering, Chongqing Jiaotong University, Chongqing 400074, China \\ ${ }^{2}$ National Engineering Research Centre for Inland Waterway Regulation, Chongqing Jiaotong University, \\ Chongqing 400074, China \\ ${ }^{3}$ State Key Laboratory of Bridge Structure Dynamics, \\ China Merchants Chongqing Communications Research \& Design Institute Co, Chongqing 400074, China
}

Correspondence should be addressed to Lunliang Duan; duanll@cqjtu.edu.cn

Received 8 December 2020; Revised 18 January 2021; Accepted 1 March 2021; Published 17 March 2021

Academic Editor: Shangtong Yang

Copyright $(2021$ Lei Xing et al. This is an open access article distributed under the Creative Commons Attribution License, which permits unrestricted use, distribution, and reproduction in any medium, provided the original work is properly cited.

To explore the pile-soil interaction response in saturated sand under long-term horizontal cyclic loading, a series of indoor $1 \mathrm{~g}$ model tests were carried out with self-made loading equipment. In this paper, the self-made loading system and test program are introduced firstly. Then, the long-term horizontal cyclic loading-induced pile top cumulative displacement, the rotation angle, the mono-pile horizontal cyclic stiffness, the cyclic $p-y$ curve, the pore water pressure, the soil settlement, and cracks around monopile are fully studied. Based on the experimental results, the pile-soil interaction response shows a two-stage characteristic with the change in cycle $(N)$, and the short-term effects of horizontal cyclic loading are greater than the long-term effects. In the first 1000 cycles, the cumulative displacement of pile top, the rotation angle of mono-pile, and the pore water pressure could reach more than $90 \%$ of the final value. In addition, the cyclic $p-y$ curve obtained by the test is generally smaller than the $p-y$ curve calculated from the API specification, and the soil near the mono-pile will settle with annular cracks under the cyclic loading.

\section{Introduction}

In the past decade, with the continuous development of science and technology and the sustainable development needs of clean and environment-friendly energy, offshore wind power has entered a period of rapid development [1-5]. Offshore wind power generation which has attracted great attention due to its advantages of stable wind resources, high wind speed, large power generation, and no occupation of land resources has a good development prospect [6]. In recent years, with the decrease in onshore wind energy resources, wind farm construction shows a trend of transferring from land to offshore [7]. From 2009 to 2019, China's cumulative installed capacity of offshore wind power increased by 253 times, from $17.5 \mathrm{MW}$ to 4,429.9 MW. Large-diameter single pile foundation is widely used in offshore wind turbine engineering. Located in a complex marine environment, offshore wind power foundation will undergo permanent lateral cumulative deformation under cyclic loading such as wind, tide, wave current, and ocean current. A host of studies have shown that when the rotation angle of pile shaft exceeds $0.5^{\circ}$, the offshore wind turbine will not work normally [8]. Therefore, it is of great significance to study the long-term loading response of offshore wind power foundation under horizontal cyclic loading for the design and stability evaluation of offshore wind power foundation [9].

Long-term loading test of the single pile in saturated sand is the most direct method to investigate the long-term loading characteristics of single pile in saturated sand under horizontal cyclic loading. The long-term loading test of single pile foundation is divided into field test and model test. In field tests, Little et al., Long et al., and Lin et al. proposed empirical formulas for cumulative deformation of single pile foundation in sand under horizontal cyclic loading through field tests [10-12]. These formulas are 
mainly in exponential and logarithmic forms, but they are essentially $p-y$ curve stiffness weakening models. Although long-term loading of a single pile can truly reflect the longterm loading response of a single pile in the field test, the preparation time of the field test is long, the test cycle is long, and the test is difficult. Therefore, most of the studies investigate the long-term loading response of a single pile through model tests. The model test includes centrifugal test and $1 \mathrm{~g}$ model test. The centrifugal test of single pile can satisfy all kinds of similarity ratio between the model and prototype, but the preparation period of the centrifugal test is long and the number of cycles is small. For example, Rosquoet et al., Klinkvort et al., and Zhang et al. conducted single pile centrifuge tests with loading cycles within 1000 cycles [13-15]. These results have little significance for predicting the long-term loading response of single pile. Compared with the single pile centrifugal test, the $1 \mathrm{~g}$ model test is difficult to overcome the deficiency caused by the similarity ratio between the model and prototype, but the $1 \mathrm{~g}$ model test can be loaded for a long time and repeated, and the difficulty in model test is relatively low. The most representative one is Leblanc et al., who conducted model tests of about $10^{4}$ cycles of cyclic loading in dry sand through a self-made long-term horizontal cyclic loading device and proposed a horizontal cyclic cumulative rotation angle prediction model, but this model is in a nonexplicit form [16]. Subsequently, Arshad et al., Chen et al., Zhu et al., and Zhang et al. further carried out long-term cyclic loading model tests of large-diameter single pile, suction bucket, and caisson pile by self-made long-term horizontal cyclic loading device [17-20]. Zhu et al. realized cyclic loading tests of suction bucket foundation for millions of cycles, and these test results have great significance for predicting the longterm loading response law of offshore buildings [21].

Compared with experimental research, the theoretical research mainly focuses on the accurate simulation of hysteresis path within dozens of internal cycles, such as the $p-y$ analysis method based on elastic foundation beam. Allotey et al. established the $p-y$ curve simulating the loading-unloading and reloading process based on the nonlinear Winkler foundation model and, at the same time, took into account the disconnecting effect of soil around the pile [22]. Heidari et al. combined Masing criterion and the cyclic attenuation model of soil with the horizontal loadbearing strain wedge SW model to simulate the cyclic hysteresis characteristics [23]. Huang and Liu proposed a nonlinear motion-hardening model based on the singlemedium metal elastoplastic model, which considered the stress-strain hysteretic property of soil on the basis of considering the elastic modulus of soil [24]. In terms of numerical simulation, Achmus et al. and Depina et al. proposed an improved stiffness attenuation model to calculate the cumulative deformation of single pile under cyclic loading through secondary development, but this model ignored the hysteresis effect of soil under cyclic loading $[25,26]$. Bourgeois et al. and Giannakos et al. realized threedimensional numerical simulation of single horizontally loaded pile by means of the motion-hardening soil model based on D-P criterion and the Mohr-Coulomb criterion and studied the dynamic response of single pile under longterm loading, respectively $[27,28]$. Based on the nonlinear Winkler foundation model, Memarpour et al. proposed a new stable and practical BNWF model by adopting the CPSI element considering decoupling, which can be used to calculate the lateral displacement characteristics of pile under the action of cyclic loading [29].

At present, a great deal of studies on the load-bearing characteristics of pile under horizontal cyclic loading have been investigated, but little attention has been paid on the cumulative deformation and resistance attenuation of soil around pile. Moreover, study of variation rules of pore water pressure within the pile-soil interface under horizontal cyclic loading is relatively less, and the loading cycles of tests of the existing researches are mostly concentrated within 1000 cycles. Therefore, the small-scale model test of single pile under horizontal cyclic loading was carried out in this paper using the self-made indoor model test cyclic loading system, and the number of cyclic loading was over $5 \times 10^{3}$ cycles to study the long-term response of mono-pile under horizontal cyclic loading. In this paper, the self-made indoor model test cyclic loading system and test scheme will be introduced in Section 2. In Section 3, the cumulative pile top displacement, the rotation angle, the mono-pile horizontal cyclic stiffness, the cyclic $p-y$ curve, the pore water pressure, and the settlement and cracking around mono-pile under horizontal cyclic loading will be analyzed in detail.

\section{Model Test}

2.1. Model Pile. During the physical model tests, the model pile is made of hollow aluminum alloy. The geometric similarity ratio of model pile and prototype pile is $1: 100$. As shown in Figure 1, the model pile has a pipe diameter of $50 \mathrm{~mm}$, a thickness of $3 \mathrm{~mm}$, and a length of $1 \mathrm{~m}$, and its elastic modulus is $71 \mathrm{GPa}$. The bottom of the model pile is sealed with a round flat-bottom aluminum cap. The model pile is embedded into the soil for $70 \mathrm{~cm}$, and the suspended section above the foundation surface is $30 \mathrm{~cm}$. In order to meet the similarity of constitution, dynamics, and motion, the critical pile length is introduced to keep the long-term loading response law of the experimental model and the prototype pile under the consistent horizontal cyclic loading. The formula of critical pile length in sand [30] is

$$
\begin{aligned}
L_{c r} & =2\left(\frac{E_{e} I_{e}}{n_{0}}\right)^{1 / 5}, \\
L_{c f} & =4\left(\frac{E_{e} I_{e}}{n_{0}}\right)^{1 / 5},
\end{aligned}
$$

where $L_{c r}$ and $L_{c f}$ are the critical pile length of rigid pile and flexible pile, respectively; $E_{e}$ and $I_{e}$ are the elastic modulus and sectional moment of inertia of pile foundation, respectively; and $n_{0}$ is the initial reaction coefficient of foundation, which can be calculated by the relationship curve given by Terzaghi [31], as shown in Figure 2. The $n_{0}$ calculated in this model test is shown in Table 1. The pile used in this model test is semirigid pile. 


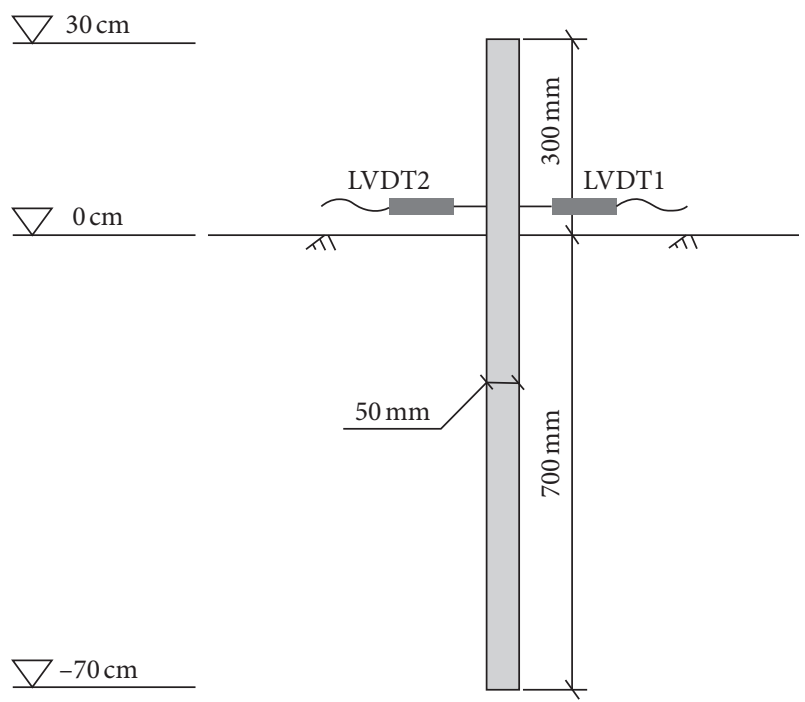

FIGURE 1: Layout of model pile.

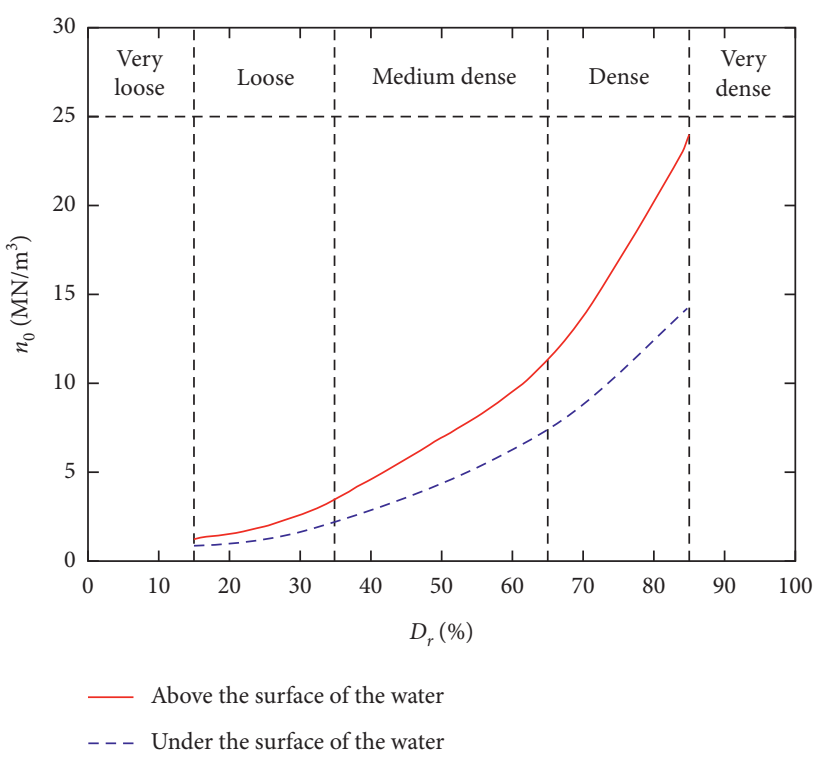

FIgURE 2: Relationship curve between $n_{0}$ and $D_{r}$ of sand.

TABLE 1: Critical pile length.

\begin{tabular}{lccccc}
\hline Soil & $\rho_{d}$ & $D_{r}$ & $n_{0}$ & $L_{c r}$ & $L_{c f}$ \\
\hline Sand & 1.54 & 60.3 & 6.3 & 0.53 & 1.06 \\
\hline
\end{tabular}

2.2. Model Sand. The sand used in the model test is local river sand, which is thoroughly washed and dried. As shown in Table 2, the dry density is $1.542 \mathrm{~g} / \mathrm{cm}^{3}$, the compactness is $60.3 \%$, and the relative density is 2.64 . The grading curve of the soil is shown in Figure 3. In the test, the filling thickness of soil in the model box is $0.8 \mathrm{~m}$, which is prepared by layered filling and rolling. The filling steps of soil are as follows: (1) the model pile is fixed in the centre of the test box and keeps the pile body upright. (2) A scale is pasted on the toughened glass on both sides of the test box to control the filling thickness of each layer and the total filling thickness. The
TABLE 2: Model test parameters.

\begin{tabular}{lcc}
\hline Parameter & Symbol & Value \\
\hline Soil properties & & \\
Mean grain size & $d_{50}(\mathrm{~mm})$ & 0.175 \\
Dry density & $\rho_{d}\left(\mathrm{~g} / \mathrm{cm}^{3}\right)$ & 1.541 \\
Specific gravity of sediment grain & $G_{s}$ & 2.64 \\
Poisson's ratio & $\mu_{s}$ & 0.32 \\
Maximum void ratio & $e_{\max }$ & 0.856 \\
Minimum void ratio & $e_{\min }$ & 0.427 \\
Void ratio & $E$ & 0.597 \\
Relative density & $D_{r}$ & 0.603 \\
\hline Pipe properties & & \\
Diameter & $D(\mathrm{~mm})$ & 50 \\
Thickness & $h_{l}(\mathrm{~mm})$ & 3 \\
Length & $L(\mathrm{~mm})$ & 1000 \\
Elastic modulus & $E(\mathrm{GPa})$ & 71 \\
Poisson's ratio & $\mu_{p}$ & 0.3 \\
\hline Loading properties & & \\
Frequency & $f(\mathrm{~Hz})$ & 1 \\
\hline
\end{tabular}

filling thickness of each layer of soil is $30 \mathrm{~mm}$. After the even filling is completed, iron blocks with a diameter of $200 \mathrm{~mm}$ and thickness of $60 \mathrm{~mm}$ are used for compaction. According to the designed rolling times, the designed dry density is achieved. (3) After filling the soil, water is added into the model box and the test is conducted after standing for 24 hours. At the same time, the water depth of about $10 \mathrm{~mm}$ should be kept throughout the test.

2.3. Test Device. The foundation of in-service offshore wind power will endure billions of cycles of cyclic loading with different amplitudes in the service life; for example, Achmus et al. found that the number of cycles would exceed $10^{8}$ [25]. Therefore, the complex load borne by the offshore wind power foundation is simplified into a simple periodic cyclic loading in the test. At the same time, a self-designed longterm horizontal cyclic loading system was used to carry out model tests, as shown in Figure 4. The loading system consists of power system, sliding system, loading regulation system, connection system, and reaction system. The power system consists of a motor, an eccentric wheel, and a motor step-down frequency regulator, which mainly provides loading power with different frequencies and amplitudes for this model test. The sliding system is mainly composed of connecting rod and linear slider bearing, which mainly ensures the directional loading of this model test. The loading regulation system is mainly composed of special coupling and tension pressure sensor, which is mainly used to adjust and measure the cyclic loading in the test. The connection system mainly refers to the connection mode between the model pile and the loading regulation system, and different loading paths can be realized through different connection modes. The reaction system is mainly a reaction steel frame, which is mainly used to reduce mechanical vibration, provide reaction force, and prevent dumping. This test can achieve horizontal cyclic loading with different amplitudes, different cycles, different frequencies, and different loading paths, which meet the requirements of this 


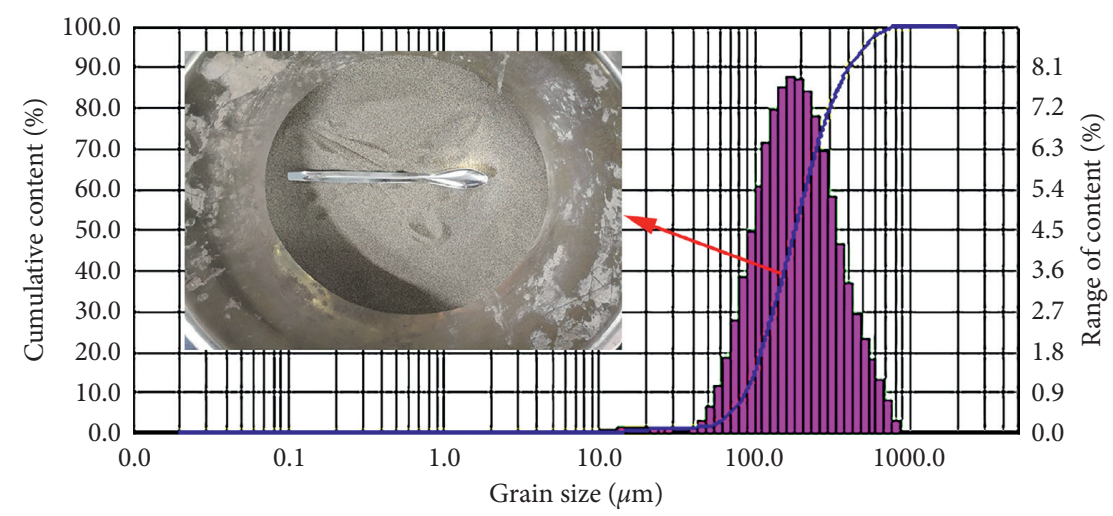

FIGURE 3: Grading curve and sand sample.

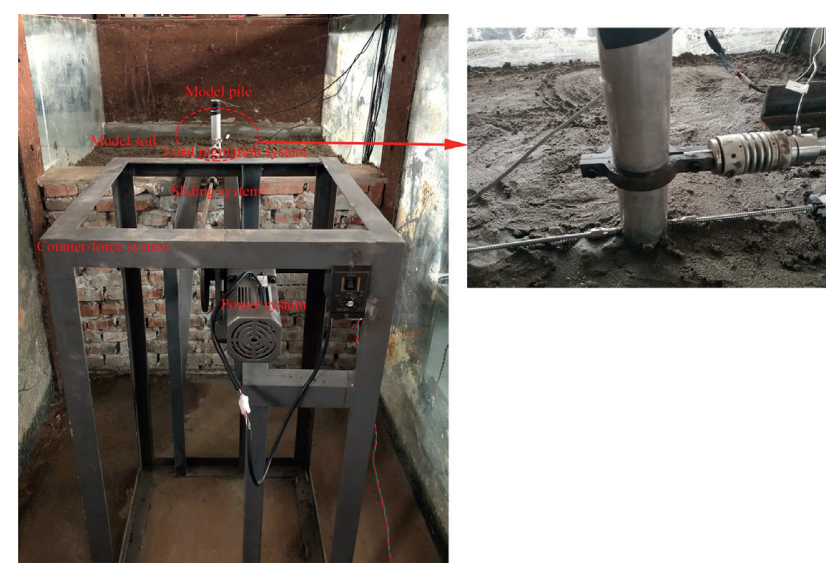

FIgURE 4: Schematic diagram of test device.

model test. In the test, the loading curve obtained by tension and compression sensor is shown in Figure 5.

The size of the model box is $1.2 \mathrm{~m} \times 1.35 \mathrm{~m} \times 0.9 \mathrm{~m}$, and the distance between the model pile and the edge of the model box is greater than $10 D$ ( $D$ is the pile diameter), which meets the requirements of boundary conditions, so the boundary effect can be ignored. The layout of the sensors in the test is shown in Figure 6.

2.4. Test Program. In this test, 16 channels of Donghua DH5922 dynamic signal acquisition system were used to collect test data. In order to ensure the progress of the test, the following situations occur in the model test: (1) when the number of cycles reaches 5000; (2) when the displacement at the mud surface exceeds $0.2 \mathrm{D}$.

In the study, the horizontal ultimate bearing capacity of the model pile is determined through the horizontal static loading test and the slow maintenance loading method is adopted in the model test. When the displacement of the pile body at the mud surface exceeds $0.2 D[32,33]$, loading is stopped. At this time, it is considered that the loading corresponding to the displacement of $0.2 \mathrm{D}$ in the loadingdisplacement curve (Figure 7) obtained from the test is the ultimate bearing capacity of the model pile. And the ultimate bearing capacity of the model pile is $120 \mathrm{~N}$. Leblanc et al. suggested that the ratio of cyclic loading amplitude to static ultimate bearing capacity should be adopted [16]. Therefore, in this paper, the ratio of horizontal cyclic loading amplitude $\left(H_{c}\right)$ to horizontal ultimate bearing capacity $\left(H_{u}\right)$ is defined as horizontal cyclic loading ratio $\left(\eta_{c}\right)$. The test conditions are shown in Table 3. Considering the frequency of wave loading and wind loading in marine environment, Hesham et al. suggested that the loading frequency of model test should be $0-1 \mathrm{~Hz}$ [34], so the loading frequency in this model experiment is $1 \mathrm{~Hz}$. In order to maintain the waveform, a frequency sampling of $10 \mathrm{~Hz}$ was used in the test.

\section{Results and Discussion}

3.1. The Cumulative Deformation of Mono-Pile under Horizontal Cyclic Loading. Previous studies have shown that the pile top's cumulative lateral displacement [24] and rotation angle [16] of mono-pile foundation in saturated sand will increase continuously under lateral cyclic loading. And the phenomenon of weakening appears as shown in macroscopic view. In this section, the cumulative deformation law of large-diameter mono-pile in saturated sand based on the mono-pile model test results under different amplitudes and cycles will be analyzed. Figure 8 shows the variation in cumulative deformation of model pile top with the number of cycles, where $N$ is the number of cycles, $y$ is the displacement of pile top, and $\theta$ is the rotation angle of the mono-pile top. Figure 9 displays the variation in maximum cumulative displacement and rotation angle of model pile top with $\eta_{c}$.

As shown in Figure 8(a), when the amplitude of horizontal cyclic loading is small $\left(0.125 \leq \eta_{c} \leq 0.5\right)$, the cumulative displacement of pile top increases rapidly in the first 1000 cycles. Then, the increasing speed of cumulative displacement at the top of pile gradually slows down and tends to be stable. When the amplitude of horizontal cyclic loading is large $\left(0.625 \leq \eta_{c}\right)$, the cumulative displacement of pile top increases rapidly in the first 1000 cycles. When the number of cycles $N$ is 5000 cycles, the cumulative displacement of pile top still increases. Therefore, the critical lateral cyclic loading ratio $\left(\eta_{c \min }, \eta_{c \max }\right)$ is assumed in the paper. When $\eta_{c}$ is less than or equal to $\eta_{c \mathrm{~min}}$, the horizontal accumulated displacement of pile top will not accumulate with the 


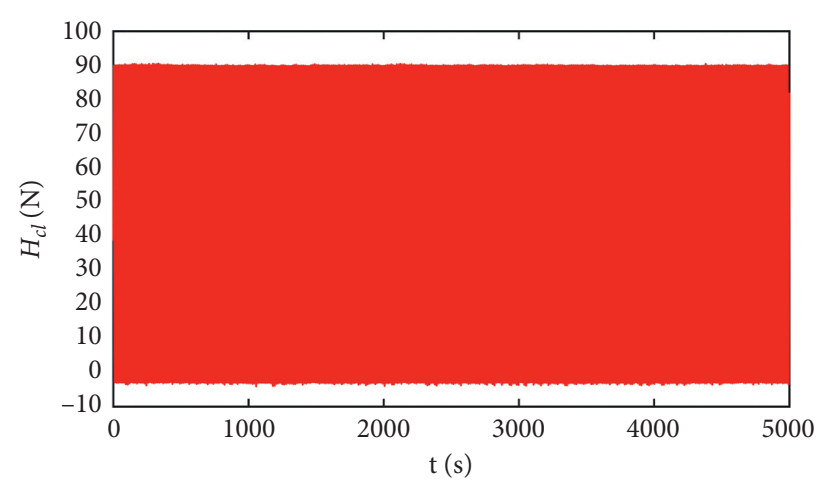

(a)

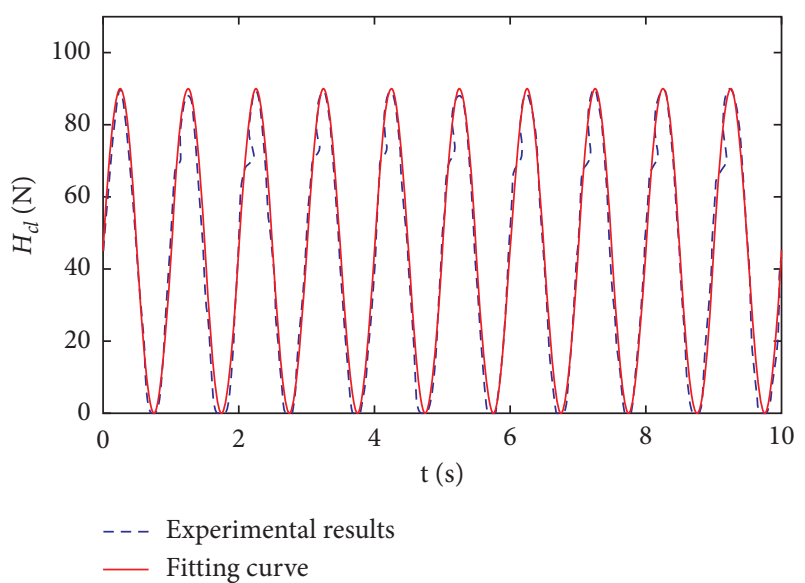

(b)

FIGURE 5: Variation curve of horizontal cyclic loading: (a) output loading of device; (b) fitting curve.

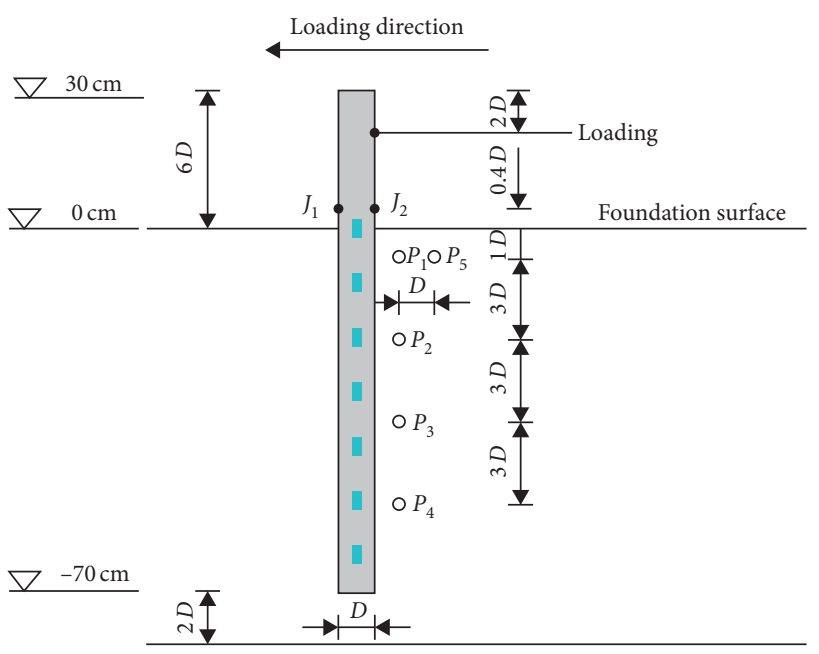

- Displacement meter

○ Pore pressure gauge

- Strain gauge

Figure 6: The sensor layout.

increase in the number of cycles. When $\eta_{c}$ is less than or equal to $\eta_{c \max }$, the horizontal accumulated displacement of pile top increase with the increase in cycles, and the horizontal accumulated displacement of pile top will not increase at the later stage of the cycle. As shown in Figure 8(b), the variation trend of the cumulative rotation angle of model pile top is consistent with pile top cumulative displacement. It further indicates the existence of critical horizontal cyclic loading ratio. Therefore, when the design of large-diameter mono-pile foundation is considered for restraining pile foundation deformation, it is recommended to control $\eta_{c \max }$ within 0.5 .

As shown in Figure 9, when $\eta_{c} \leq 0.25$, the maximum cumulative displacement of pile top and the rotation angle of model pile increase slowly with the increase in horizontal cyclic loading ratio. When $\eta_{c} \leq 0.25$, the maximum

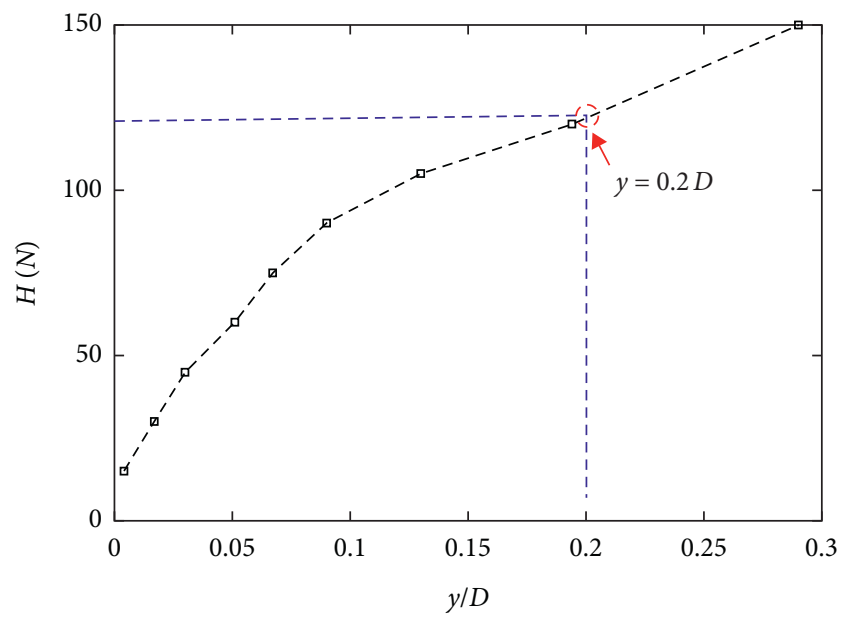

FIgURE 7: The curve of static loading-displacement.

TABle 3: Experiment conditions.

\begin{tabular}{lcc}
\hline & Horizontal cyclic loading ratio $\left(\eta_{c}\right)$ & Cycles $(N)$ \\
\hline Case 1 & 0.125 & 5000 \\
Case 2 & 0.25 & 5000 \\
Case 3 & 0.375 & 5000 \\
Case 4 & 0.5 & 5000 \\
Case 5 & 0.625 & 5000 \\
Case 6 & 0.75 & 5000 \\
\hline
\end{tabular}

cumulative displacement of pile top and the cumulative rotation angle of model pile develop rapidly with the increase in horizontal cyclic loading ratio. This paper argues that, in saturated sand, when the horizontal cyclic loading amplitude is small, the internal strain of the soil around the single pile is small, the soil structure has not been damaged, and the stiffness of the soil around the pile decreases slowly so that the soil deformation is small, resulting in a small cumulative displacement of the mono-pile. When the horizontal cyclic loading amplitude is large, the internal strain of soil around a 

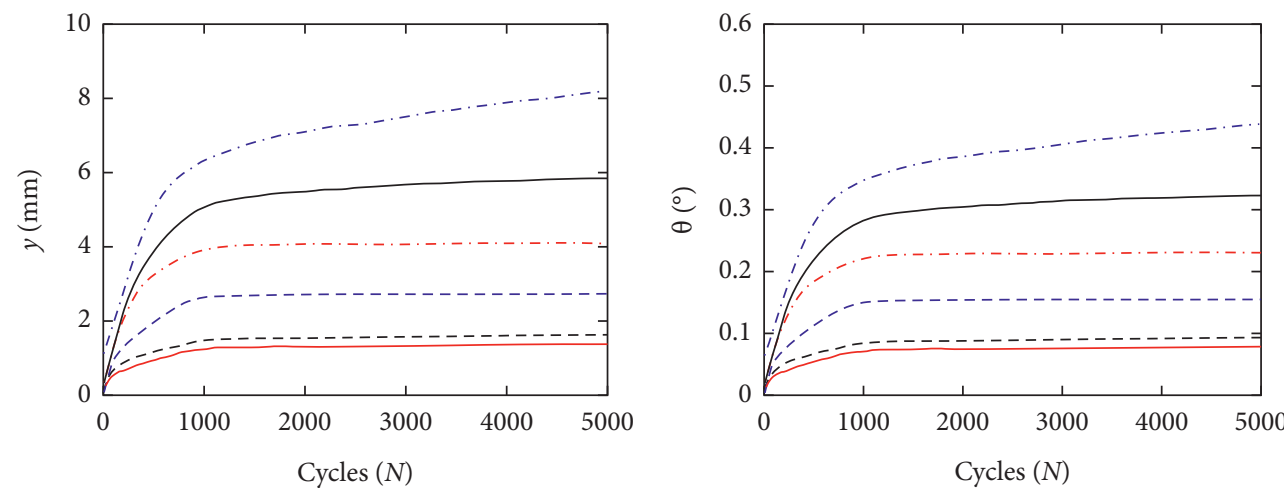

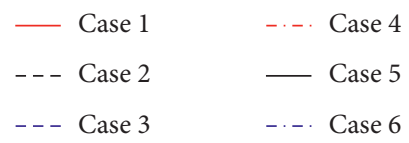

(a)

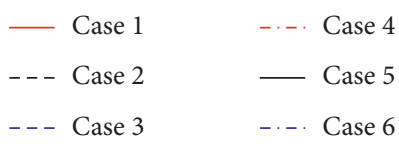

(b)

Figure 8: Variation in cumulative deformation of model pile top with the number of cycles: (a) cumulative displacement of pile top; (b) rotation angle of model pile top.

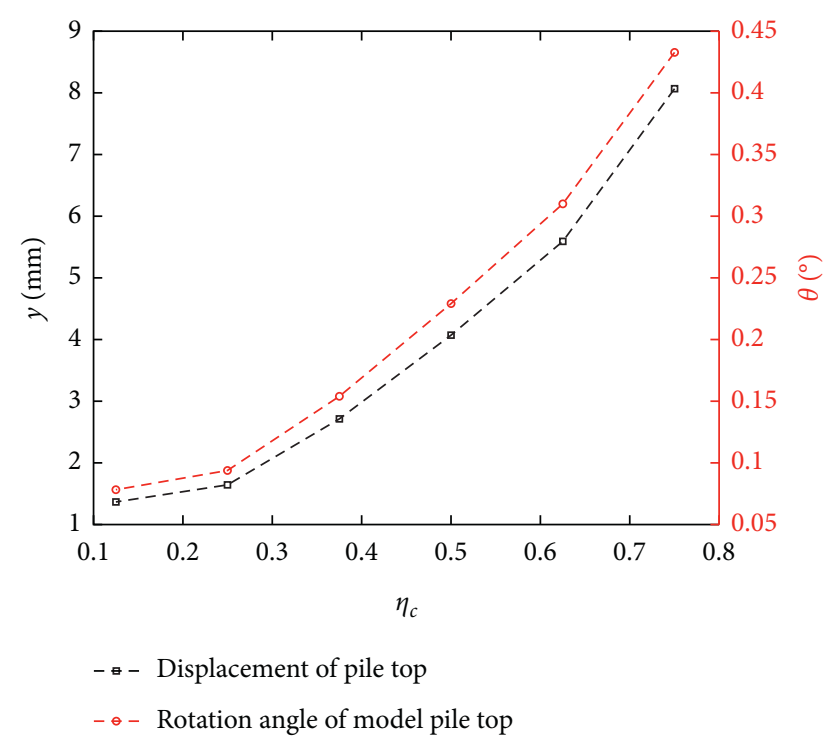

FIgURE 9: Variation in maximum cumulative displacement and the rotation angle of model pile top with $\eta_{c}(N=5000)$.

mono-pile is large. With the rapid development of the number of cycles, the structure of soil will be destroyed in a short time, and the stiffness attenuation of soil will be accelerated, which is finally manifested as the rapid increase in accumulation of displacement mono-pile.

3.2. The Horizontal Cyclic Stiffness of Mono-Pile. As shown in Figure 10, in order to further reflect the cumulative deformation characteristics of single pile under long-term horizontal cyclic loading, the cyclic loading and deformation increment mode is adopted, and the calculation method for the horizontal cyclic stiffness of mono-pile is constructed by considering the maximum displacement $\left(y_{c \max }\right)$, minimum displacement $\left(y_{c \min }\right)$, and the variation in the amplitude of

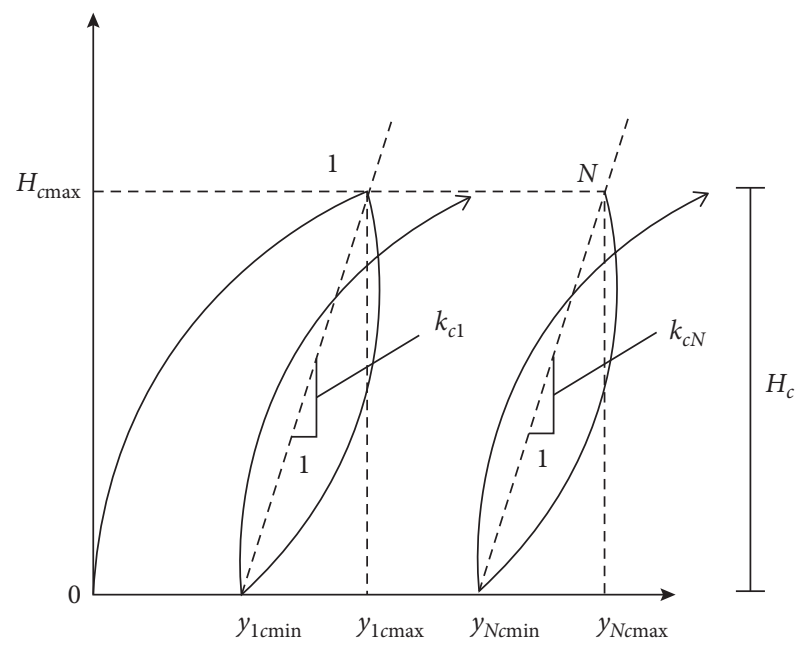

FIgURE 10: Calculation method of horizontal cyclic stiffness of single pile.

horizontal cyclic loading $\left(H_{c}\right)$ of the three parameters of the cyclic loading path, so as to reflect the variation law of the horizontal cyclic stiffness of single pile under the action of horizontal cyclic loading:

$$
k_{c}=\frac{H_{c}}{\left(y_{c \max }-y_{c \min }\right) D} k_{c}=\frac{H_{c}}{\left(y_{c \max }-y_{c \min }\right) D},
$$

where $k_{c}$ is the he horizontal cyclic stiffness of mono-pile. Figure 10 shows the variation in cyclic stiffness of single pile with cycles.

As shown in Figure 11, the horizontal cyclic stiffness of the mono-pile increases with increase in the cyclic loading cycles. As the cycles increase, the difference between the maximum $\left(y_{c \max }\right)$ and minimum $\left(y_{c \min }\right)$ values of the displacement within a single cycle keeps decreasing. The minimum value $\left(y_{c \min }\right)$ of the displacement produced within 


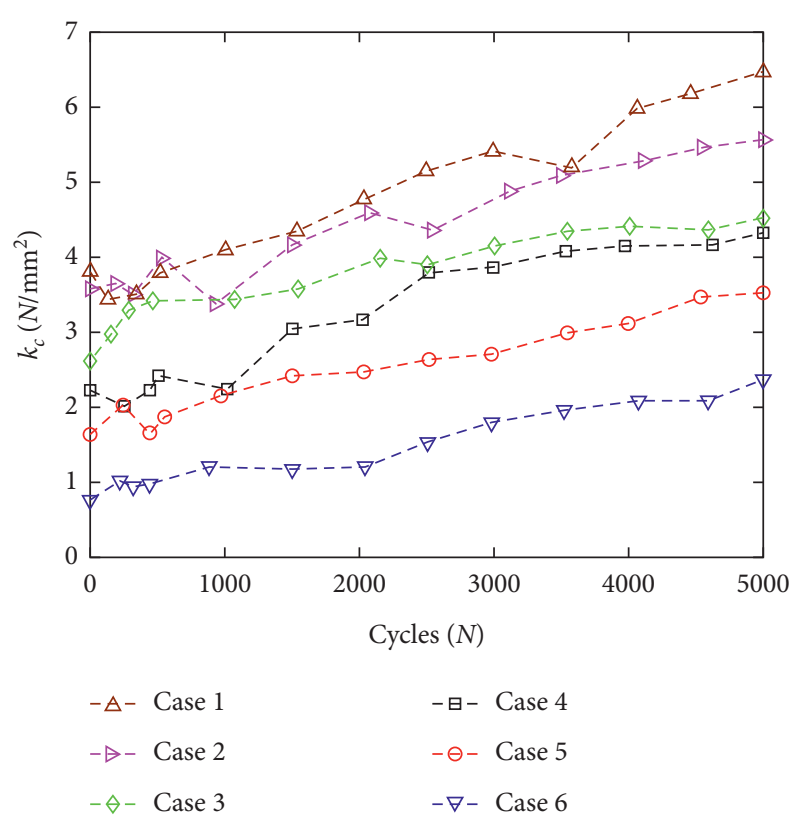

FIgURE 11: Variation in cyclic stiffness of mono-pile with cycles.

a cycle is constantly converging to the maximum value $\left(y_{c \max }\right)$. This indicates that as the cycles increase, the cumulative deformation of the mono-pile foundation tends to balance, which is consistent with the results in Section 3.1. It is noteworthy that as the cyclic loading amplitude increases, the lateral cycle stiffness of the mono-pile decreases. As the cyclic loading amplitude increases, the difference between the maximum and minimum displacement within a single cycle increases. This means that as the cyclic loading amplitude increases, the cumulative deformation of the monopile foundation increases.

3.3. The Cyclic $p-y$ Curve. In order to study the cyclic $p-y$ curves of large-diameter mono-pile foundations under cyclic loading, this paper mainly relies on the results of Section 3.1 (Figure 9) to analyze the cyclic $p-y$ curves of mono-pile foundation at different depths under different conditions within 5000 cycles in this section. According to the model test results, the authors adopted the method suggested by Yang and Liang, to obtain the $p-y$ curve under cyclic loading [35]. It can be expressed by the following equation:

$$
\begin{aligned}
M(z) & =\frac{E_{e} I_{e} \varepsilon}{c} M(z)=\frac{E_{e} I_{e} \varepsilon}{c}, \\
p & =-\frac{\mathrm{d}^{2} M}{\mathrm{~d} z^{2}}, \\
y & =\iint \frac{M}{E_{e} I_{e}} \mathrm{~d} z^{2} y=\iint \frac{M}{E_{e} I_{e}} \mathrm{~d} z^{2},
\end{aligned}
$$

where $c$ is the radius of the pile, $E_{e} I_{e}$ is the bending stiffness of the pile, $\varepsilon$ is the measured strain value at a specific depth $(z)$ along the buried length of the pile, $p$ is the soil resistance, and $y$ is the displacement of the pile.
In order to obtain the $p-y$ curve, the two steps are involved [36]: (1) according to the measured strain of single pile, the bending moment of single pile is calculated by equation (3); (2) $p$ and $y$ are calculated according to equations (4) and (5), respectively. The two boundary conditions are used for equation (5): one boundary condition is the tip of single pile with zero displacement, and another boundary condition is obtained from the displacement measured by using LVDT1 and LVDT2. Figure 12 shows the variation in moment of single pile with depth, and Figure 13 shows the cycle $p-y$ curves, based on the experimental results.

As shown in Figure 13, the $p-y$ curve at different depths is degraded as the cycles increase. The variation trend is consistent with that of single pile bending moment (Figure 12). This shows that the stiffness of the soil around the mono-pile decreases and the soil weakens as the cycles increase, which leads to the accumulation of pile top displacement. As the loading amplitude increases, the degradation of the $p-y$ curve at the same depth increases. And the displacement at the same depth develops rapidly. When $\eta_{c}$ is 0.75 , the displacement at the same depth keeps an increasing trend with the increase in the cycles, which further indicates the existence of a maximum critical loading ratio. In summary, at the same depth, a larger loading amplitude has a greater effect on the soil around the pile foundation and the stiffness attenuation is more pronounced. In addition, under the effect of the same loading amplitude, the loading change gradually decreases as the depth increases. And the stiffness attenuation keeps increasing. The attenuation of the $p-y$ curve is mainly concentrated in the shallow layer $(1 D)$. When the loading amplitude $\left(\eta_{c}=0.75\right)$ is larger, the influence of the $p-y$ curve slightly decreases. This is consistent with the findings of Matlock [37].

According to API's standards [38, 39], the comparisons between the calculated results and the test results are given in Figure 14. On the whole, the displacement values obtained for API's standards under the same soil resistance are smaller than the test results. Therefore, the calculation results according to API standards will overestimate the bearing performance of large-diameter pile foundations under lateral cyclic loading.

3.4. The Cumulative Pore Water Pressure at Mono-Pile Side under Cyclic Loading. Under cyclic loading, the pore water pressure in the vicinity of mono-pile foundations in saturated silt sand soils can accumulate. It may further lead to the decrease in the effective stress in the sandy soil. Eventually, the bearing properties of the pile foundation will continue to deteriorate [40]. Therefore, based on the model test results in case 4 , the pattern of pore water pressure variation near the pile-soil interface is studied in this section. Figure 15 shows the normalized curves of pore water pressure variation at different depths near a mono-pile. $p_{e}$ is the pore water pressure amplitude, and $\sigma_{z}^{\prime}$ is the vertical effective stress at the same depth.

As shown in Figure 15, the pore water pressure near the mono-pile increases as the cycles increase. The pore water 


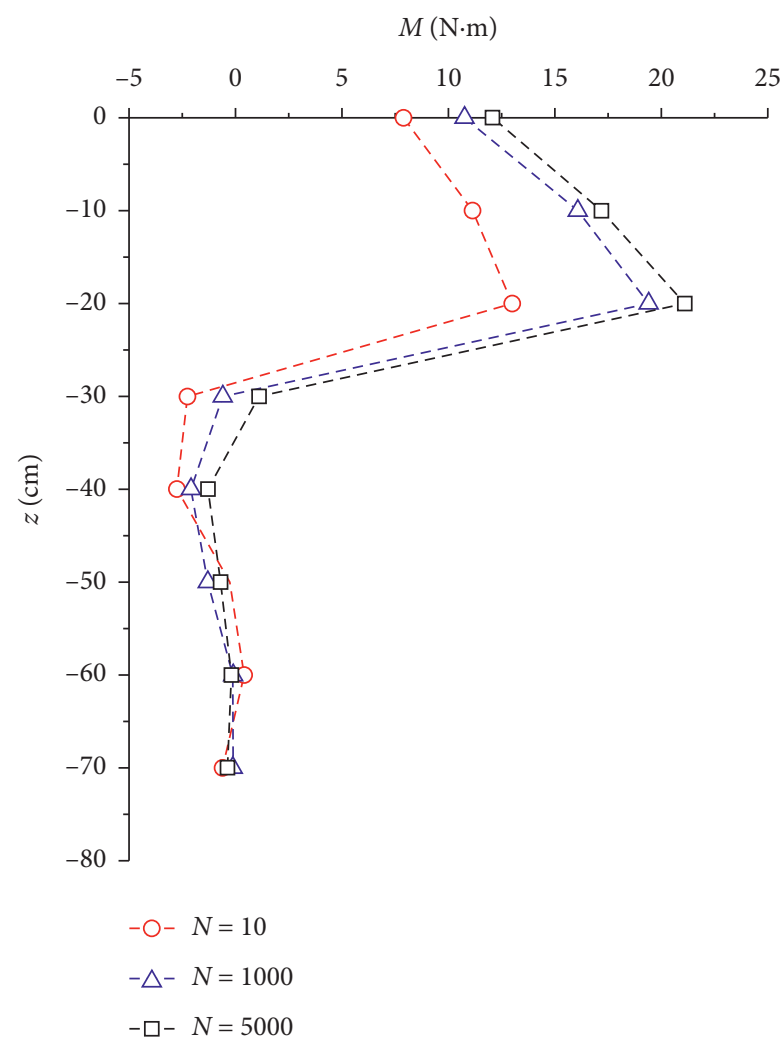

FIgURE 12: Variation in moment of single pile with depth.

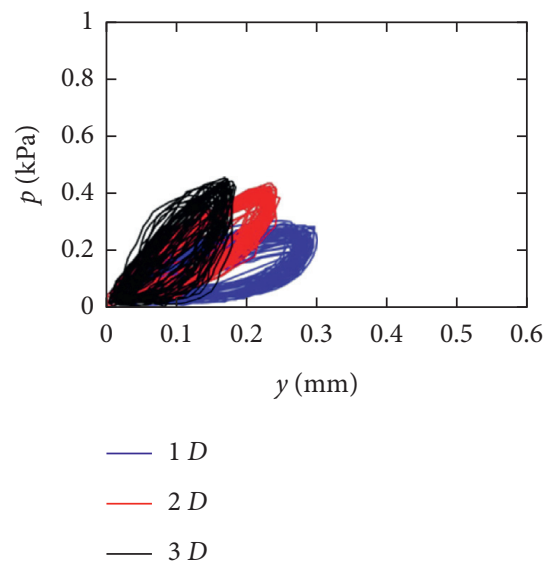

(a)
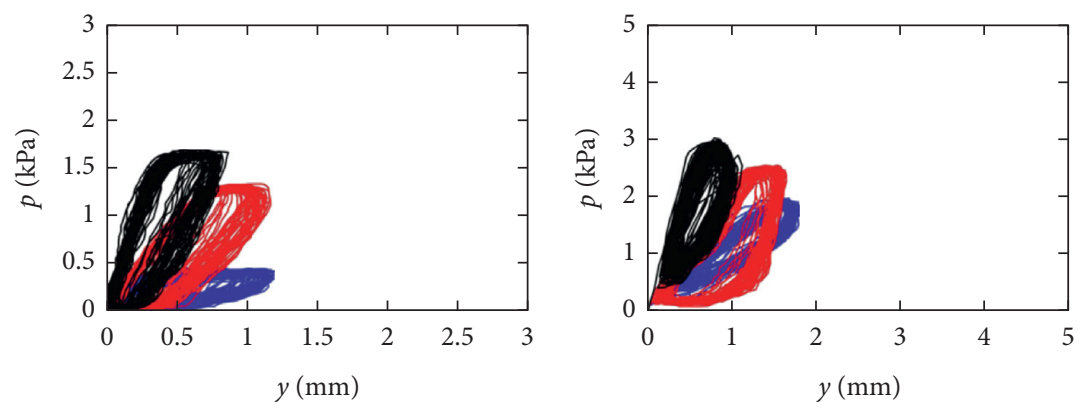

$-1 D$

$-1 D$

$-2 D$

$-2 D$

$-3 D$

(b)

(c)

Figure 13: Continued. 

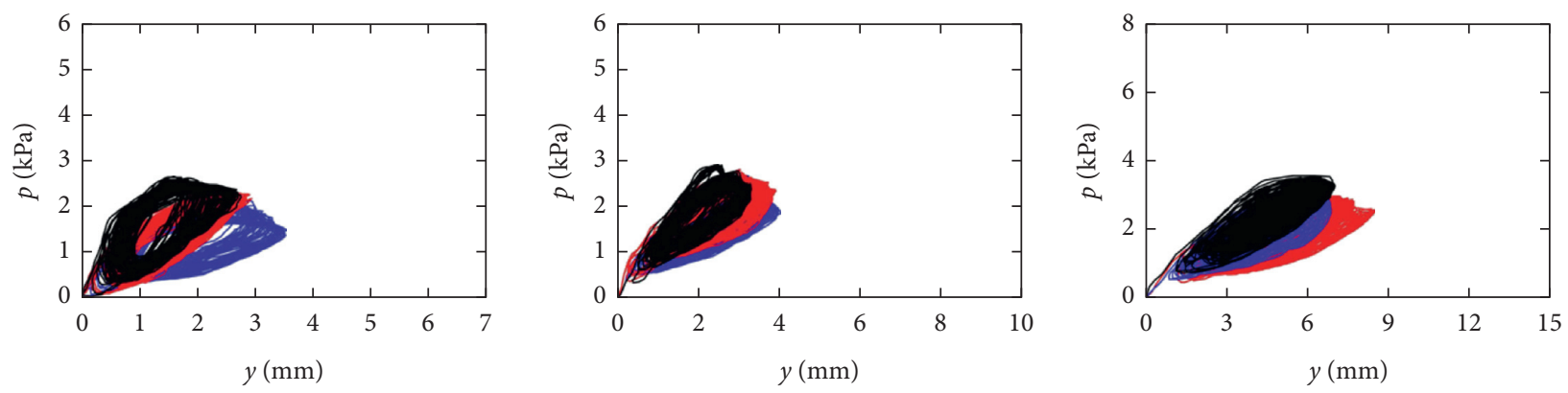

$-1 D$
$-\quad 2 D$
$-\quad 3 D$

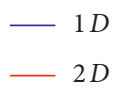

$-1 D$

$-2 D$

- $3 D$

$-3 D$

(d)

(e)

(f)

Figure 13: Cycle $p$ - $y$ curve: (a) case 1; (b) case 2; (c) case 3; (d) case 4; (e) case 5; (f) case 6.
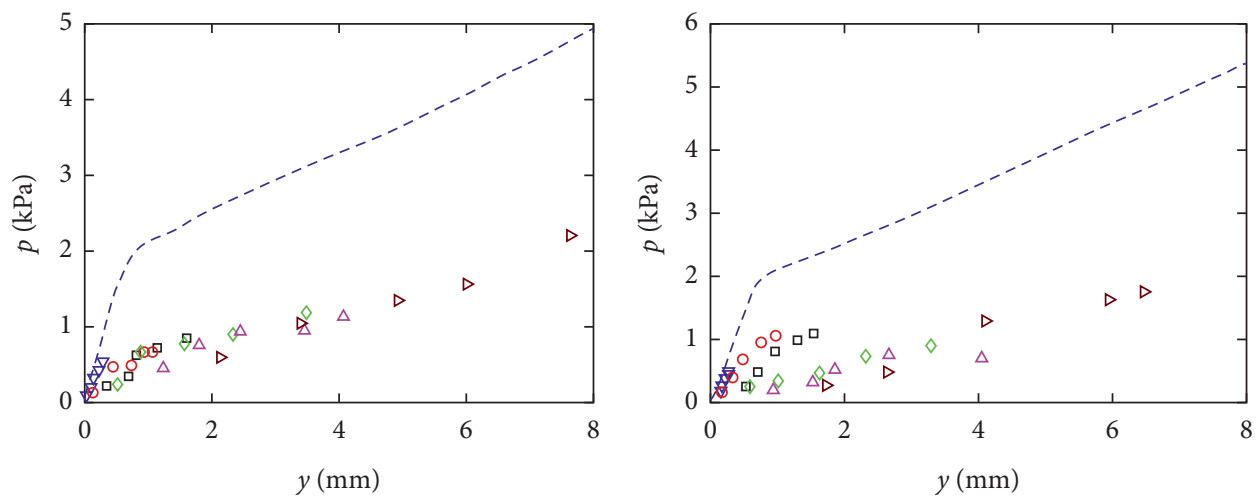

$\begin{array}{lc}\nabla \text { Case } 1 & \triangle \text { Case } 5 \\ \circ \text { Case } 2 & \triangleright \text { Case } 6 \\ \square \text { Case } 3 & -- \text { API } \\ \diamond \text { Case } 4 & \end{array}$

(a)

$$
\begin{aligned}
& \nabla \text { Case } 1 \\
& \circ \text { Case } 2 \\
& \square \text { Case } 3 \\
& \diamond \text { Case } 4
\end{aligned}
$$$$
\Delta \quad \text { Case } 5
$$$$
\triangleright \quad \text { Case } 6
$$

(b)

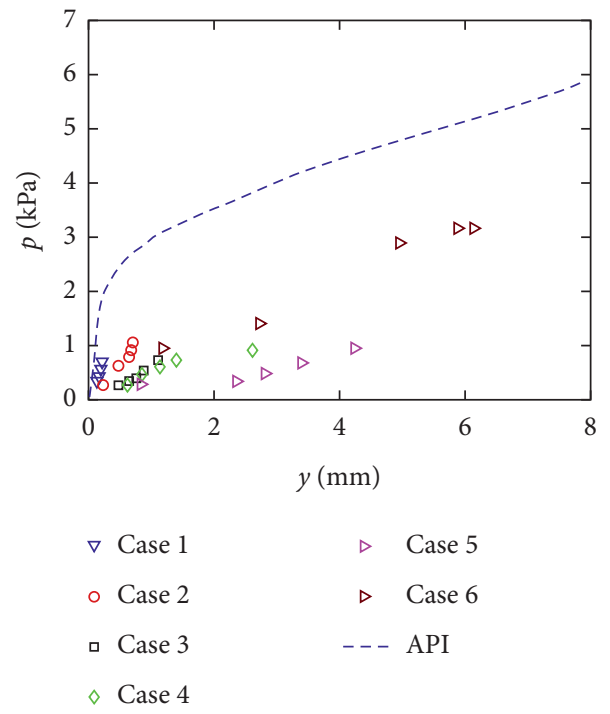

(c)

Figure 14: The test results were compared with API: (a) $1 D$; (b) $2 D$; (c) $3 D$. 


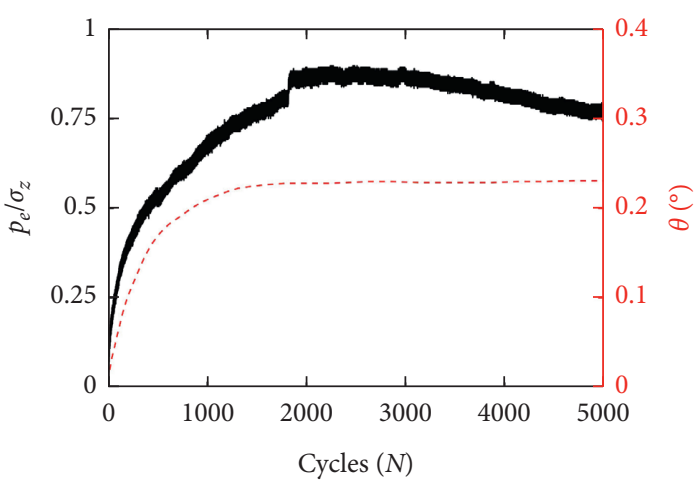

— Pore water pressure

- - - Rotation angle of model pile top

(a)

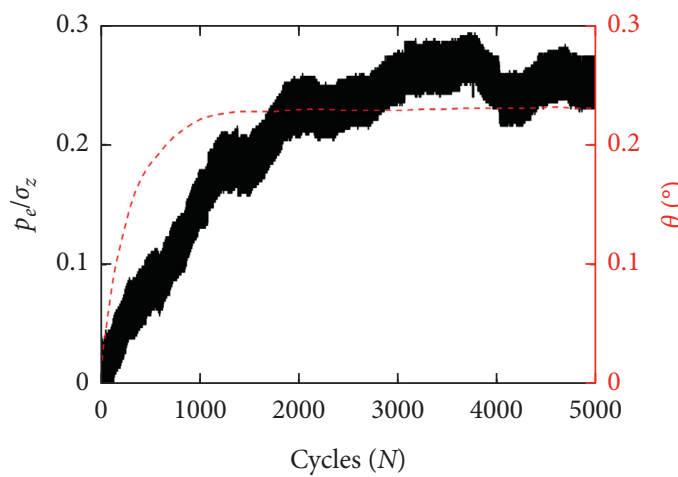

Cycles $(N)$

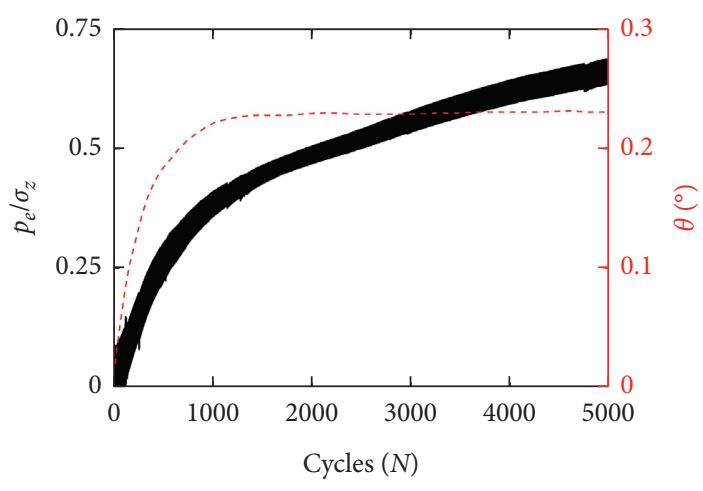

— Pore water pressure

- - - Rotation angle of model pile top

(b)

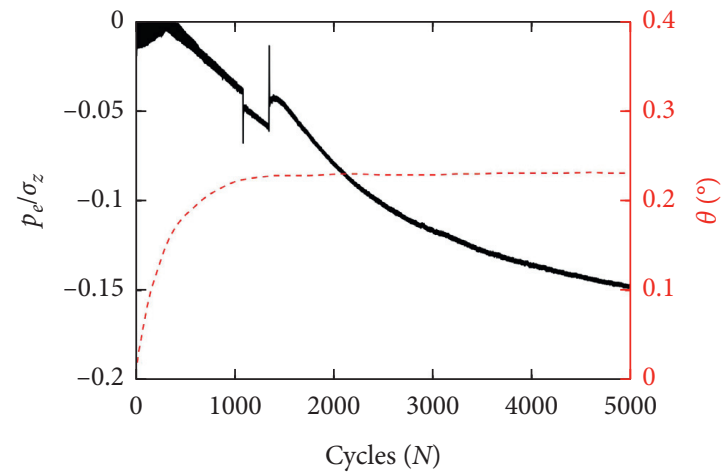

_ Pore water pressure

_ - - Rotation angle of model pile top

(d)

(c)

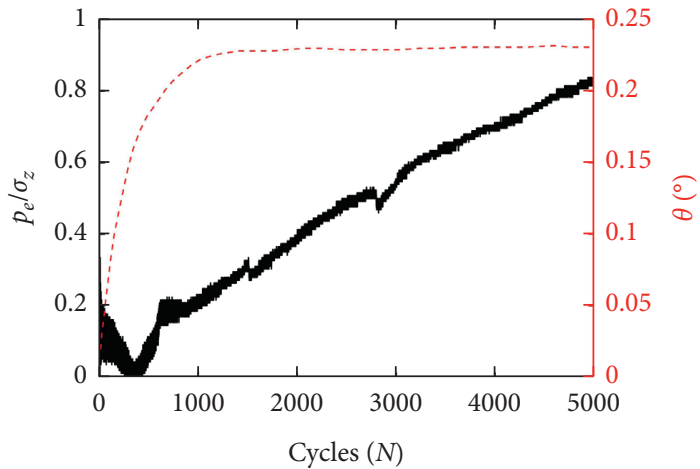

_ Pore water pressure

- - - Rotation angle of model pile top

(e)

Figure 15: Variation in pore water pressure: (a) $P 1$; (b) $P 2$; (c) $P 3$; (d) $P 4$; (e) $P 5$

pressure develops rapidly at the first 1000 cycles and then the increasing trend slows down. The pore water pressures of $P 1$, $P 2$, and $P 3$ follow the same trend. The pore water pressures continued to accumulate and finally are stabilized. However, the pore water pressure in $P 1$ tended to decrease. This is because $P 1, P 2$, and $P 3$ are located at depths of $1 D, 4 D$, and
$7 D$, respectively. Under horizontal cyclic loading, the pore water in the soil around the pile could not be removed quickly, which led to an increasing pore water pressure. The pore water pressure of $P 4$ is negative. With the increase in the number of cycles, the pore water pressure keeps accumulating. It is believed that the negative pressure occurs 


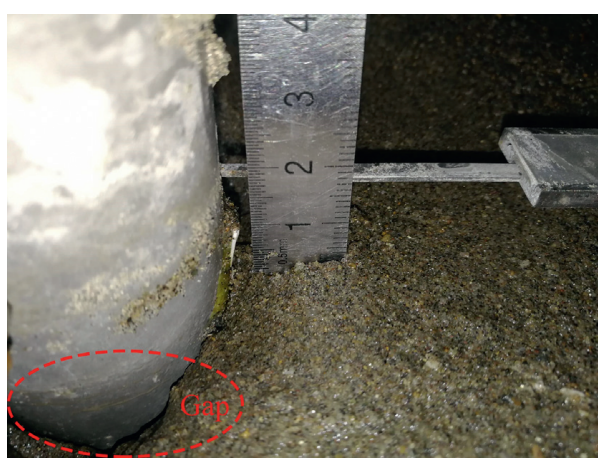

(a)

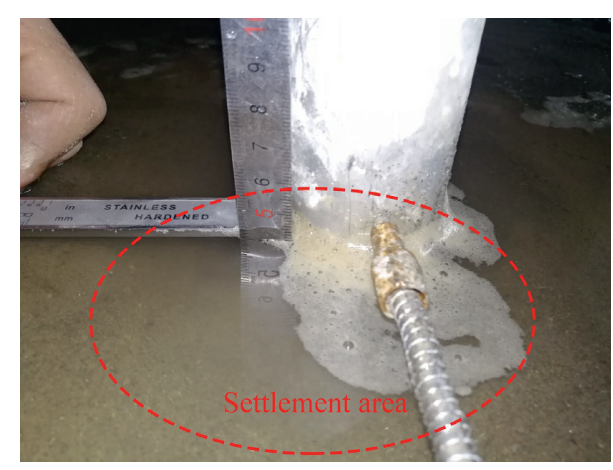

(b)

Figure 16: The gap and the settlement around pile: (a) case 2; (b) case 6.

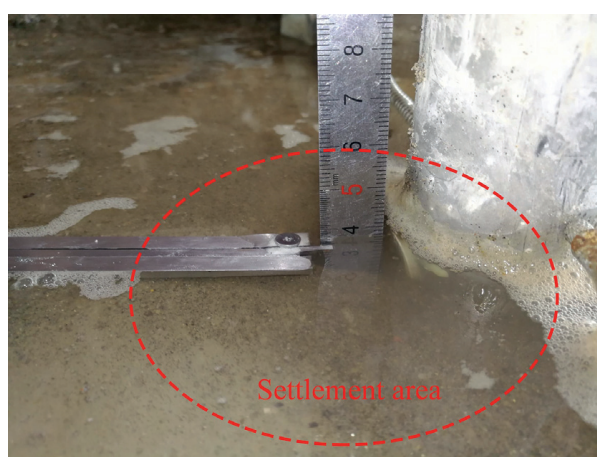

(a)

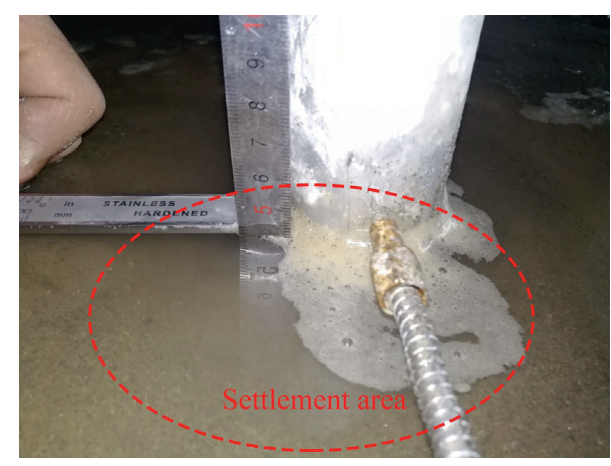

(b)

Figure 17: Settlement with different cycles around pile in case 6: (a) $N=1000$ cycles; (b) $N=5000$ cycles.

mainly because $P 4$ is located in the opposite direction of the pile movement and a suction situation occurs, which in turn exhibits negative pressure during the test. The phenomenon is similar to that of Liao et al. and Bauer et al. in the monopile model test in clay $[36,41]$. The pore water pressure of $P 5$ continued to accumulate with increasing number of cycles, and the increasing trend slightly decreased. In addition, the maximum value of pore water pressure of $P 5$ is less than the maximum value of pore water pressure of $P 1$. $P 5$ decreases by about $22 \%$ relative to $P 1$. This indicates that the pore water pressure decayed in the range of $1 D$ at the pile circumference.

\subsection{The Cumulative Pore Water Pressure at Pile Side under} Cyclic Loading. In this test, sedimentation and cracks in the soil around the pile at the muddy surface under cyclic loading are local damage phenomena of the pile-soil system under horizontal loading. Therefore, in this section, the development pattern of settlement and cracks in the soil around the pile at the muddy surface under cyclic loading will be analyzed in detail. Figure 16 shows the soil gaps and the settlements around pile. Figure 17 shows the settlement with different cycles around pile. Figure 18 shows the variation in the settlement depth with the loading amplitude.

As shown in Figure 16, under horizontal cyclic loading, clear settlement and cracks appeared around the mono-pile.

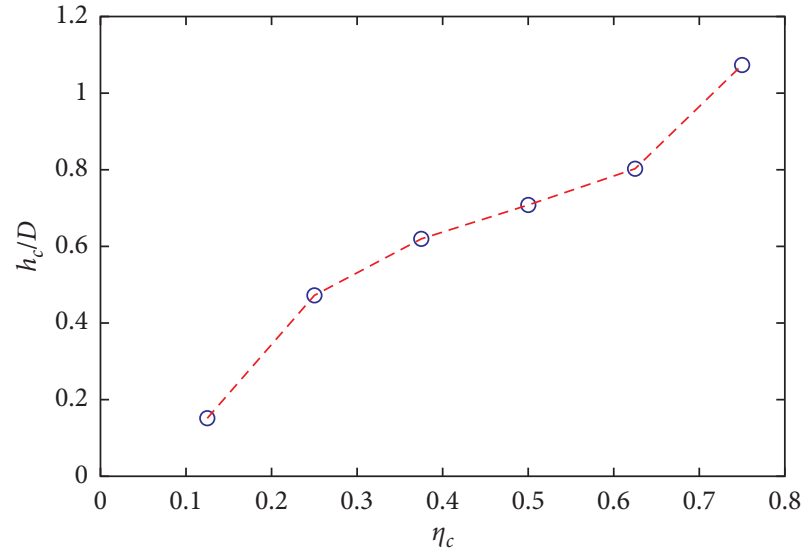

FIGURE 18: Variation in the settlement depth with the loading amplitude.

Under the cyclic loading, the soil around the pile appears to settle into an approximately circular pit. Circular cracks appeared at the bottom of the circular pit. The above phenomena indicate that the soil structure around the mono-pile is continuously adjusted under the cyclic loading and the pore water pressure is accumulating. Under the coupling effect of pore water pressure and soil structure adjustment, the soil around the mono-pile sinks continuously. And the sinking phenomenon becomes more and 
more obvious as the cycles increase. At the same time, cracks appear at the muddy surface.

\section{Conclusions}

In this paper, the pile-soil interaction response in saturated sand under horizontal cyclic loading was investigated by the $1 \mathrm{~g}$ model test, where 6 groups of horizontal cyclic tests with different loading amplitudes were carried out by selfmade loading test system. Under the horizontal cyclic loading, the cumulative displacement of pile top, the rotation angle of mono-pile, the mono-pile horizontal cyclic stiffness, the cyclic $p-y$ curve, the pore water pressure, and the settlement and gaps around mono-pile are fully studied. Based on the experimental results, the following conclusions are drawn:

(1) Under the horizontal cyclic loading, the cumulative displacement of pile top and the rotation angle of mono-pile show a trend of increasing at first and then decreasing as cycles increase, and the maximum cumulative displacement of pile top increases with the increase in loading amplitude.

(2) The critical horizontal cyclic loading ratio $\left(\eta_{c \max }\right)$ should be existed in judging the cumulative law of the pile. In other words, the horizontal displacement of pile top will not accumulate with cyclic loading when the horizontal cyclic loading ratio is less than the critical horizontal cyclic loading ratio and the cumulative horizontal displacement of pile top increases rapidly and does not tend to be stable in the later stage when the horizontal cyclic loading ratio is larger than the critical horizontal cyclic loading ratio.

(3) The variation trend of the horizontal cyclic stiffness of mono-pile is opposite to the cumulative deformation of mono-pile. The horizontal cyclic stiffness of single pile increases with the increase in the number of cycles and the horizontal cyclic stiffness of mono-pile decreases with the increase in loading amplitude.

(4) The cyclic weakening continues to weaken with the increase in depth, and the weakening phenomenon mainly occurs within $50 \mathrm{~mm}$ from the surface. The cyclic $p-y$ curve obtained from the API specification is generally larger than the measured value.

(5) The horizontal cyclic loading-induced pore water pressure near mono-pile increases continuously, and the variation in pore water pressure was up to $22 \%$ in the $50 \mathrm{~mm}$ range.

(6) The soil settlement around the mono-pile mainly occurred within the first 1000 cycles, and the circumferential cracks appeared in the test should be noticed.

\section{Data Availability}

The data used to support the findings of this study are available from the corresponding author upon request.

\section{Conflicts of Interest}

The authors declare that they have no conflicts of interest.

\section{Acknowledgments}

The authors gratefully acknowledge the support from the National Natural Science Foundation of China (Grant no. 51979017), the Youth Project of Science and Technology Research Rrogram of Chongqing Education Commission of China (Grant no. KJQN-201900709), the China Postdoctoral Science Foundation (Grant no. 2020M683228), and the research start-up funds from Chongqing Jiaotong University (Grant no. 19JDKJC-BO12).

\section{References}

[1] S.-P. Breton and G. Moe, "Status, plans and technologies for offshore wind turbines in Europe and North America," Renewable Energy, vol. 34, no. 3, pp. 646-654, 2009.

[2] P. T. Pedersen, "Marine structures: future trends and the role of universities," Engineering, vol. 1, no. 1, pp. 131-138, 2015.

[3] S.-J. Feng, S.-F. Lu, and Z.-M. Shi, "Field investigations of two super-long steel pipe piles in offshore areas," Marine Georesources \& Geotechnology, vol. 34, no. 6, pp. 559-570, 2016.

[4] L. Duan, D.-S. Jeng, and D. Wang, "PORO-FSSI-FOAM: seabed response around a mono-pile under natural loadings," Ocean Engineering, vol. 184, pp. 239-254, 2019.

[5] L. Duan and D. Wang, "Novel three-dimensional numerical model for residual seabed response to natural loadings near a single pile," Applied Ocean Research, vol. 94, p. 102004, 2020.

[6] J. Firestone, A. W. Bates, and A. Prefer, "Power transmissionwhere the offshore wind energy comes home," Environmental Innovation and Societal Transitions, vol. 29, pp. 90-99, 2018.

[7] H. P. Dong, Q. K. Wang, and Y. Ding, "Assessment of sea area condition and development potential of wind farm in Shandong province," Wind Energy, vol. 22, no. 2, pp. 70-73, 2019.

[8] L. Arany, S. Bhattacharya, J. Macdonald, and S. J. Hogan, "Design of monopiles for offshore wind turbines in 10 steps," Soil Dynamics and Earthquake Engineering, vol. 92, pp. 126152, 2017.

[9] D. Kong, Y. Liu, M. Deng, and X. Zhao, "Analysis of influencing factors of lateral soil resistance distribution characteristics around monopile foundation for offshore wind power," Applied Ocean Research, vol. 97, p. 102106, 2020.

[10] R. L. Little and J. L. Briaud, Full Scale Cyclic Lateral Load Tests on Six Single Piles in Sand (No. TAMU-RR-5640), Texas A and M University, College Station, TX, USA, 1988.

[11] J. H. Long and G. Vanneste, "Effects of cyclic lateral loads on piles in sand," Journal of Geotechnical Engineering, vol. 120, no. 1, pp. 225-244, 1994.

[12] S.-S. Lin and J.-C. Liao, "Permanent strains of piles in sand due to cyclic lateral loads," Journal of Geotechnical and Geoenvironmental Engineering, vol. 125, no. 9, pp. 798-802, 1999.

[13] F. Rosquoët, L. Thorel, J. Garnier, and Y. Canepa, "Lateral cyclic loading of sand-installed piles," Soils and Foundations, vol. 47, no. 5, pp. 821-832, 2007.

[14] R. T. Klinkvort, C. T. Leth, and O. Hededal, "Centrifuge modelling of a laterally cyclic loaded pile," in Proceedings of the 7th International Conference on Physical Modelling in 
Geotechnics, Zurich, Switzerland, June 2010.

[15] C. Zhang, D. White, and M. Randolph, "Centrifuge modeling of the cyclic lateral response of a rigid pile in soft clay," Journal of Geotechnical and Geoenvironmental Engineering, vol. 137, no. 7, pp. 717-729, 2011.

[16] C. Leblanc, G. T. Houlsby, and B. W. Byrne, "Response of stiff piles in sand to long-term cyclic lateral loading," Géotechnique, vol. 60, no. 2, pp. 79-90, 2010.

[17] M. Arshad and B. C. O'Kelly, "Development of a rig to study model pile behaviour under repeating lateral loads," International Journal of Physical Modelling in Geotechnics, vol. 14, no. 3, pp. 54-66, 2014.

[18] R.-P. Chen, Y.-X. Sun, B. Zhu, and W. D. Guo, "Lateral cyclic pile-soil interaction studies on a rigid model monopile," Proceedings of the Institution of Civil Engineers-Geotechnical Engineering, vol. 168, no. 2, pp. 120-130, 2015.

[19] B. Zhu, B. W. Byrne, and G. T. Houlsby, "Long-term lateral cyclic response of suction caisson foundations in sand," Journal of Geotechnical and Geoenvironmental Engineering, vol. 139, no. 1, pp. 73-83, 2013.

[20] C. Zhang, X. Zhang, M. Huang, and H. Tang, "Responses of caisson-piles foundations to long-term cyclic lateral load and scouring," Soil Dynamics and Earthquake Engineering, vol. 119, pp. 62-74, 2019.

[21] F. Y. Zhu, C. D. O’Loughlin, B. Bienen, M. J. Cassidy, and N. Morgan, "The response of suction caissons to long-term lateral cyclic loading in single-layer and layered seabeds," Géotechnique, vol. 68, no. 8, pp. 729-741, 2018.

[22] N. Allotey and M. H. El Naggar, "A numerical study into lateral cyclic nonlinear soil-pile response," Canadian Geotechnical Journal, vol. 45, no. 9, pp. 1268-1281, 2008.

[23] M. Heidari, M. Jahanandish, H. El Naggar, and A. Ghahramani, "Nonlinear cyclic behavior of laterally loaded pile in cohesive soil," Canadian Geotechnical Journal, vol. 51, no. 2, pp. 129-143, 2014.

[24] M. Huang and Y. Liu, "Axial capacity degradation of single piles in soft clay under cyclic loading," Soils and Foundations, vol. 55, no. 2, pp. 315-328, 2015.

[25] M. Achmus, Y. S. Kuo, and K. Abdel-Rahman, "Behavior of monopile foundations under cyclic lateral load," Computers and Geotechnics, vol. 36, no. 5, pp. 725-735, 2009.

[26] I. Depina, T. M. Hue Le, G. Eiksund, and T. Benz, "Behavior of cyclically loaded monopile foundations for offshore wind turbines in heterogeneous sands," Computers and Geotechnics, vol. 65, pp. 266-277, 2015.

[27] E. Bourgeois, M. H. J. Rakotonindriana, A. Le Kouby, P. Mestat, and J. F. Serratrice, "Three-dimensional numerical modelling of the behaviour of a pile subjected to cyclic lateral loading," Computers and Geotechnics, vol. 37, no. 7-8, pp. 999-1007, 2010.

[28] S. Giannakos, N. Gerolymos, and G. Gazetas, "Cyclic lateral response of piles in dry sand: finite element modeling and validation," Computers and Geotechnics, vol. 44, pp. 116-131, 2012.

[29] M. M. Memarpour, M. Kimiaei, M. Shayanfar, and M. Khanzadi, "Cyclic lateral response of pile foundations in offshore platforms," Computers and Geotechnics, vol. 42, pp. 180-192, 2012.

[30] M. J. Tomlinson, Pile Design and Construction Practice, pp. 222-236, Viewpoint Publications, London, UK, 1977.

[31] K. Terzaghi, "Evalution of conefficients of subgrade reaction," Géotechnique, vol. 5, no. 4, pp. 297-326, 1955.

[32] L. Zhang, F. Silva, and R. Grismala, "Ultimate lateral resistance to piles in cohesionless soils," Journal of Geotechnical and Geoenvironmental Engineering, vol. 131, no. 1, pp. 78-83, 2005.

[33] S. Malhotra, "Design and construction considerations for offshore wind turbine foundations in North American," in Wind Turbines, I. Al-Bahadly, Ed., pp. 231-264, In Tech, Rijeka, Croatia, 2007.

[34] M. Hesham, E. I. Naggar, and K. J. Bentley, "Dynamic analysis for laterally loaded piles and dynamic $p-y$ curves," Canadian Geotechnical Journal, vol. 37, pp. 1166-1183, 2000.

[35] K. Yang and R. Liang, "Methods for deriving $p-y$ curves from deviced lateral load tests," Geotechnical Testing Journal, vol. 30, no. 1, pp. 1-8, 2006.

[36] W. Liao, J. Zhang, J. Wu, and K. Yan, "Response of flexible monopile in marine clay under cyclic lateral load," Ocean Engineering, vol. 147, pp. 89-106, 2018.

[37] H. Matlock, "Correlations for design of laterally loaded piles in soft clay," in Proceeding of 2nd Annual Offshore Technology Conference, pp. 577-594, Houston, TX, USA, April 1970.

[38] American Petroleum Institute, Recommended Practice for Planning, Designing and Constructing Fixed Offshore Platforms-Working Stress Design, API Recommended Practice 2AWSD, Washington, DC, USA, 22th edition, 2014.

[39] American Petroleum Institute, Geotechnical and Foundation Design Considerations, ANSI/API Recommended Practice 2GEO, Washington, DC, USA, 2014.

[40] M. Ashour and G. Norris, "Lateral loaded pile response in liquefiable soil," Journal of Geotechnical and Geoenvironmental Engineering, vol. 129, no. 5, pp. 404-414, 2003.

[41] J. Bauer, H.-G. Kempfert, and O. Reul, "Lateral pressure on piles due to horizontal soil movement," International Journal of Physical Modelling in Geotechnics, vol. 16, no. 4, pp. 173184, 2016. 